WellBeing International

WBI Studies Repository

1996

\title{
Gender Differences in Attitudes Toward Animal Research
}

Jennifer J. Eldridge

University of New Mexico

John P. Gluck

University of New Mexico

Follow this and additional works at: https://www.wellbeingintlstudiesrepository.org/acwp_arte

Part of the Animal Experimentation and Research Commons, Animal Studies Commons, and the Other Anthropology Commons

\section{Recommended Citation}

Eldridge, J. J., \& Gluck, J. P. (1996). Gender differences in attitudes toward animal research. Ethics \& behavior, 6(3), 239-256.

This material is brought to you for free and open access by WellBeing International. It has been accepted for inclusion by an authorized administrator of the WBI Studies Repository. For more information, please contact wbisr-info@wellbeingintl.org.

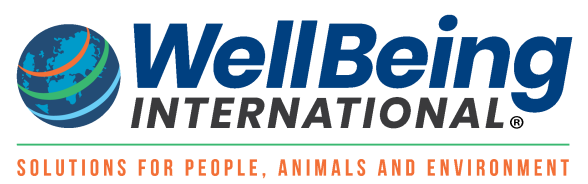




\title{
Gender Differences in Attitudes Toward Animal Research
}

Jennifer J. Eldridge and John P. Gluck

University of New Mexico

\begin{abstract}
$\underline{\text { ABSTRACT }}$
Although gender differences in attitudes toward animal research have been reported in the literature for some time, exploration into the nature of these differences has received less attention. This article examines gender differences in responses to a survey of attitudes toward the use of animals in research. The survey was completed by college students and consisted of items intended to tap different issues related to the animal research debate. Results indicated that women were more likely than men to support tenets of the animal protection movement. Likewise, women were more likely than men to favor increased restrictions on animal use and were more concerned than men about the suffering of research animals. Analysis of item contents suggested that women endorsed items reflecting a general caring for animals, were more willing than men to make personal sacrifices such as giving up meat and medical benefits in an effort to protect animals, and were more likely than men to question the use of animals in research on scientific grounds. Men, on the other hand, tended to emphasize the potential benefits arising from the use of animals in research.
\end{abstract}

Recently, evidence has accumulated that strongly suggests that men and women tend to differ in their views regarding the use of animals in research. For instance, Pifer, Shimizu, and Pifer ( 1994 ), studying an international sample, reported that in all 15 nations studied, women were more likely than men to disagree with the statement: "Scientists should be allowed to do research that causes pain and injury to animals like dogs and chimpanzees if it produces new information about human health problems" (p. 98).

In the United States, Pious (1991) found that female animal rights activists reported more involvement in the protection movement and stronger beliefs about the use of animals in research than male activists. In addition, female activists reported longer associations with the movement than men, were more likely than men to value nonhuman life at or above the level of human life, and were vegetarians or vegans more often than male activists. Female activists were also more likely to support the elimination of all animal research. Gallup and Beckstead (1988) found similar gender differences in their sample of college 
students. Results of their study indicated that overall, women were more concerned about pain and suffering in animals than men.

Recently, Herzog and Galvin (in press) used a 20-item survey of attitudes toward various human uses of animals and found that women were significantly more "sympathetic" than men toward the plight of animals used in research, educational settings, agriculture, and recreation. However, because the article did not include the scale items, it is not possible to capture the aspects of animal use that discriminated between the genders.

Kellert and Berry (1987) also found that women differ in their views toward the use of animals in varied contexts. For instance, women expressed more opposition than men to laboratory experimentation on animals, the use of animals in rodeos, trapping animals, killing of nonendangered animals for fur, and hunting. Men seemed to have more concerns about wildlife habitats, whereas women were more inclined to oppose cruel or exploitative uses of animals. The differences obtained in this study were so pronounced that the authors proclaimed "gender is among the most important demographic influences on attitudes toward animals in our society" (p. 365).

Several hypotheses have been posited to account for gender differences in attitudes toward animal research. Jasper and Nelkin (1992) suggested that the traditional socialization of women influences their aversion to harming animals and enhances their empathy for the suffering of animals. Herzog, Betchart, and Pittman (1991) proposed that sex-role orientation, which in part can be accounted for by socialization and age, as well as sex per se, relates to attitudes toward the treatment of animals. They found a positive correlation between characterizing oneself as more feminine on the Bern Sex Role Inventory and concern for animals.

Reasons for such gender differences in attitudes toward animal research remain uncertain, in part because authors have tended to use a very limited number of attitudinal questions in their studies; or, when many items are used, scales rather than the themes represented by individual items tend to be analyzed. Items in a survey of attitudes toward animal research may reflect many different dimensions of the animal protection debate, including concern for individual animals, faith in science to yield solutions to biomedical problems through animal research, and attitudes toward the use of alternatives such as computer simulation. Reporting broad gender differences in terms of mean scale scores does little to reveal how genders differ qualitatively and also fails to illustrate the areas in which women and men tend to agree.

This article intends to determine which items on a survey-reflecting a broad array of attitudes toward issues relevant to the animal protection debate-differentiate between genders. The attitudes probed included: (a) beliefs in the potential benefits to humans resulting from animal research; (b) concern for the suffering of individual research animals; (c) willingness to make personal sacrifices, such as giving up meat and medical benefits in an effort to save animals; (d) views on alternatives to animal use; (e) attitudes about the morality of the use of animals in research; ( $f$ ) attitudes toward restrictions on the use of animals in research; $(\mathrm{g})$ beliefs about whether animals have rights; $(\mathrm{h})$ attitudes toward the rights of humans to use animals; (i) beliefs about the value of human life relative to that of animal life; and (j) faith in review boards to protect animals.

Combinations of items that discriminated between genders will be discussed and possible reasons for these differences proposed. In addition, items that failed to discriminate between genders will be identified so that the areas in which men and women tend to agree can be determined. Finally, demographic variables, such as cultural background, political orientation, and religious preferences will be 
explored to broaden understanding of how different groups may perceive issues underlying the animal research debate.

\section{METHOD}

\section{Participants}

Undergraduate college students who were enrolled in psychology courses volunteered for this study and received course credit for their participation. The sample was composed of 139 students- 52 men and 87 women. None of the participants identified themselves as animal rights activists or as formal members of organizations explicitly concerned with the use of animals in research.

Materials

Each participant received a packet containing a consent form, a demographic survey of gender, political orientation, ethnicity, etc., and the Animal Research Questionnaire (ARQ) developed by the authors. The ARQ is a 32-item survey of attitudes toward the use of animals in research. Eight of the items were developed by Gallup and Beckstead (1988). These items were modified slightly for this study and were used with permission. The items on the ARQ, described in Appendix 1, were developed to tap two broad dimensions:

1. The Pro-Animal Research scale consists of 16 items meant to measure the extent research with animals is viewed as valuable, justified, and necessary $(M=55.98, S D=12.97$, unstandardized $\alpha$ coefficient $=.87$ ).

2. The Animal Protection scale, which also consists of 16 items, was designed to measure concern for research animals and the belief that animal research should be restricted $(M=56.51, S D=14.72$, unstandardized $\alpha$ coefficient $=.90$ ).

The protection and pro-animal research items on the ARQ were presented in an intermixed order and rated on a scale from 1 (strongly disagree) to 6 (strongly agree). Scores were derived by adding the Likert ratings endorsed across the 16 items on each scale. Thus, higher scores on a scale indicated more agreement, with a score of 96 (16 items $\times 6$ ) indicating complete agreement, and a score of 16 (16 items $\times 1$ ) indicating complete disagreement with a scale. Scores ranged from 23 to 86 on the Animal Protection scale, and from 19 to 84 on the Pro-Animal Research scale.

\section{Procedure}

All participants read a consent form and signed it when they felt sufficiently informed. Each participant then completed the survey packet and was debriefed. The experiment lasted approximately 30 min.

\section{RESULTS}

\section{Statistical Properties of the Scales and Factor Analysis}

As anticipated, a significant negative correlation was obtained between the ProAnimal Research and Animal Protection scales, $r=-.73, p<.0001$. To determine if the ARQ measured different constructs or facets of students' attitudes toward animal research, an exploratory factor analysis of the ARQ was conducted with principal components analysis followed by varimax rotation. The analysis yielded seven eigenvalues above 1.0. A three-factor solution determined by a scree plot resulted, which accounted for $48.1 \%$ of the variance. Factor loadings below \pm .30 and items with close loadings on more than one factor were omitted from further analysis of the factor scales. Appendix 2 illustrates the items comprising each of 
the three factors as well as item loadings on each factor. As Appendix 2 indicates, the items that loaded on Factor 1 appear to characterize a pro-research position. This first factor accounted for $33.5 \%$ of the variance and obtained an eigenvalue of 10.71 . Factor 2 consisted of items reflecting an animal protection stance, obtained an eigenvalue of 2.9 , and accounted for $9.1 \%$ of the variance. Items comprising Factor 3 reflected an extreme pro-research position. This factor obtained an eigenvalue of 1.8 and accounted for $5.5 \%$ of the variance.

Internal consistency reliability analyses of the three factors or scales resulted in a high unstandardized a coefficient of $.92, M=52.27, S D=12.79$, for the pro-research factor, and a moderately high $\alpha$ of $.83, M=$ $28.64, S D=7.19$, for the animal protection scale. The third factor, which reflected an extreme proresearch stance, had relatively low reliability as is indicated in an $\alpha=.54, M=8.73, S D=3.04$.

The three factors were moderately correlated. Specifically, the protection factor was negatively correlated with the pro-research factor, $r=-.51, p<.05$, and with the extreme pro-research factor $r=-.38, p<.05$. The pro-research factor and the extreme pro-research factor were positively correlated, $r=.41, p<.05$.

\section{Political Party Affiliation}

An analysis of variance (ANOVA) was conducted to determine if Democrats ( $n=69)$, Republicans $(n=$ 32 ), and Independents $(n=21)$ differed significantly on the scales and was found to be nonsignificant for both the Pro-Animal Research scale, $F=1.67, p=.17$, and the Animal Protection scale, $F=2.1, p=.10$. Republicans had the highest score on the Pro-Research scale $(M=60)$, followed by Independents $(M$ $=57)$, and Democrats $(M=54)$. In contrast, Republicans had the lowest score on the Animal Protection scale $(M=52)$, followed by Independents $(M=53)$, and Democrats, who had the highest agreement score with this scale $(M=59)$. When Independents were removed from the analysis, and only Republicans and Democrats were compared, there was a significant difference on both the Animal Protection, $t=2.3, p=$ .023 (mean Republicans $=52$, mean Democrats $=59$ ), and Pro-Animal Research scales, $t=2.24, p=$ .027 (Republicans $M=60$; Democrats $M=54$ ). $T$ tests for group differences on individual items indicated that six items, illustrated in Table 1, were responsible for these differences.

TABLE 1. Differences Between Democrats and Republicans on Items

Items Republicans Agreed With More Than Democrats

Most important biomedical breakthroughs are a consequence of using animals in research.

The use of animals in research is essential to improving human health and life quality.

People who want to stop or limit the use of animals in research are a threat to the future of science and medicine.

Items Democrats Agreed With More Than Republicans

Most psychological research done on animals is invalid and unnecessary.

Most biomedical research done on animals is repetitive, unnecessary and invalid.

If it were up to me, all use of animals in painful or dangerous research would be stopped today.

\section{Religious Preference}

Three main religious groups were present in the sample and included Catholics $(n=72)$, Protestants $(n=$ 38 ), and Buddhists $(n=6)$. The remainder of the sample was so sparsely scattered among Mormons, Muslims, atheists, agnostics, and others with no religious affiliation, that they could not be examined. ANOVAs, calculated with the harmonic mean because of unequal sample sizes, were found to be nonsignificant for both the Animal Protection scale, $F(2,113)=2.08, p=.12$, and the Pro-Animal Research scale, $F(2,113)=.81, p=.44$. Analyses of individual items, conducted using $t$ tests, indicated 
that Protestants and Catholics did not differ from each other on any items, but both groups differed significantly from Buddhists on five items as illustrated in Table 2. All five items were included on the Animal Protection scale, and $t$ tests indicated that Buddhists agreed significantly more with these items than Protestants or Catholics. Most notably, $100 \%$ of the Buddhists completely agreed $(M=6)$ with the statement, "It hurts me to see an animal in pain or psychological distress," whereas Catholics $(M=4.6)$ and Protestants $(M=4.9)$ agreed with this statement to a lesser extent.

\section{Cultural Background}

Despite small sample sizes in the ethnic categories of Native American $(n=7$, men $=3$, women $=4)$ and African-American $(n=7$, men $=4$, women $=3)$, it was thought that comparisons of these groups with the larger samples of Hispanic $(n=48$, men $=21$ women $=27)$ and Caucasian students $(n=75$, men $=26$, women $=49$ ) would be useful and of interest. An ANOVA, calculated using the harmonic mean, was found to be nonsignificant for both the Animal Protection, $F=.99, p=.39$, and Pro-Animal Research scales, $F=.30, p=.82$.

After item analysis using $t$ tests, significant differences, illustrated in Table 3, emerged between Native Americans and the three other groups, whereas Caucasians, Hispanics, and African Americans did not differ significantly from each other on any items. The most striking finding, which was also obtained in the Buddhist sample, was that $100 \%$ of the Native American students agreed completely $(M=6)$ with the item "It hurts me to see an animal in pain or psychological distress," while Hispanics $(M=4.4)$, Blacks $(M=$ 4.2), and Caucasians $(M=5.0)$ agreed with this statement but to a significantly lesser extent.

\section{TABLE 2. Items Comprising Differences Between Religions}

Items Buddhists Agreed With More than Protestants and Catholics

I am very concerned about pain and suffering in animals.

We need more regulations governing the use of animals in research.

We should reduce the number of animals used in research, make our techniques less painful and dangerous, or use alternatives to research animals whenever possible.

It hurts me to see an animal in pain or psychological distress.

If it were up to me, all use of animals in painful or dangerous research would be stopped today.

\section{TABLE 3. Items Comprising Cultural Differences}

Items Native Americans Agreed With More Than the Other Ethnic Groups

The use of animals in biomedical research cannot be justified and should be stopped.

Alternatives to using animals in research should be employed even if they are less effective than animal models.

It hurts me to see an animal in pain or psychological distress.

If it were up to me, all use of animals in painful or dangerous research would be stopped today.

Items Native Americans Agreed With Less Than the Other Groups

Animals held in city pounds or animal shelters should be used in biomedical research if they are to be euthanized by the pounds or shelters.

When determining the value of using animals in research, all of the past breakthroughs in science and medicine as well as all future benefits must be considered. 


\section{Gender Differences}

Mean differences between men and women on the Pro-Animal Research and Animal Protection scales were first compared. $T$ tests indicated that women were significantly more in favor of the Protection position $(M=58)$ than men $(M=53), t(1,137)=-1.98, p=.05$, and less in favor, though nonsignificantly, of the Pro-Animal Research position $(M=54)$ than men $(M=58), t(1,137)=1.42, p=.15$.

Item analyses. A discriminant function analysis was conducted to determine which combination of items maximized gender differences, and was found to be significant, $F(32,106)=1.597, p=.04$. Items were rank ordered by the magnitude of their loadings (correlations between each item and the variable gender), as illustrated in Table 4. Items in Table 4 are separated into three groups: (a) items that were endorsed most by women (and least by men), (b) items that were endorsed most by men (and least by women), and (c) items that did not discriminate between men and women.

Items endorsed most by women. All of the items agreed with more by men than women were originally designed to tap pro-research positions on the use of animals in research and were included on the ProResearch scale. All but one of the items that women agreed with more than men were from the Animal Protection scale.

As Table 4 illustrates, the four items that maximized gender differences and which women were most likely to agree with reflected a genuine caring and concern for animals' welfare. Analysis of these items indicated that women in this sample appear to be more concerned than the men about the feelings and reactions of individual research animals, feel more distressed at their suffering, and report being more willing to make sacrifices in attempt to limit the suffering of animals. Women also questioned whether experiments using animals are carefully designed and have scientific merit.

Women agreed more than men with seven additional items, though the differences between genders were not as salient as found on the previous four items. In sum, these seven items indicated that women were more in favor of eliminating all animal research, more likely to see animal and human life as equally valuable, and less convinced that there are moral grounds to justify inflicting harm on animals in an effort to save human lives.

The one item from the Pro-Research scale that women agreed with more than men was "Animals used in biomedical research do not feel as much pain as would humans used in the same research." This suggests that women may not need to see animals as identical to humans in their capacity to feel pain to find animals deserving of protection from pain and suffering inflicted on them in some biomedical research.

Items endorsed most by men. As Table 4 illustrates, the four items agreed with most by the men, and which maximized gender differences, suggest that they were more willing than the women to use animals in research with only very remote foreseeable utility. Also, men saw fewer valid alternatives to animal research than women, were more convinced of future benefits arising from animal research, and were more in favor of using animals in biomedical research generally.

Men agreed more than women with three additional items. A greater number of men believed the following: (a) that basic scientific curiosity is adequate justification for doing animal research, (b) that the most important biomedical breakthroughs were the result of animal research, and (c) that humans have a basic right to use animals in science, agriculture, and entertainment as they see fit. 
Table 4. Differences in Agreement With Items Between Men and Women ${ }^{\mathrm{a}}$

\section{Items Endorsed More Often by Women}

I have seriously considered becoming a vegetarian in an effort to save animal lives. $(M$ difference $=1.00, p=.001, r=.433)$

Most biomedical research done on animals is repetitive, unnecessary, and invalid. ( $M$ difference $=.70, p=.005, r=.349$ )

It hurts me to see an animal in pain or psychological distress. ( $M$ difference $=.50, p=.044, r=.251$ )

I am very concerned about pain and suffering in animals. ( $M$ difference $=0.45, p=.049, r=.245$ )

We should reduce the number of animals used in research, make our techniques less painful and dangerous, or use alternatives to research animals whenever possible. ( $M$ difference $=.40, p=.10, r=.203$ )

If it were up to me, all use of animals in dangerous or painful research would be stopped today. $(M$ difference $=.43, p=.13$, $r=.185)$

Human and animal life are equally valuable. ( $M$ difference $=.45, p=.14, r=.181$ )

There are no moral grounds to justify inflicting harm on animals in an attempt to benefit human beings. $(M$ difference $=.34, p=.18$, $r=.164)$

Animals used in biomedical research do not feel as much pain as would humans used in the same research. $(M$ difference $=.31$, $p=.20, r=.157)$

The use of animals in biomedical research cannot be justified and should be stopped. $(M$ difference $=.29, p=.24, r=.144)$

We need more regulations governing the use of animals in research. ( $M$ difference $=.30, p=.28, r=.132$ )

Alternatives to using animals in research should be employed even if they are less effective than animal models. $(M$ difference $=$ $.21, p=.392, r=.10)$

\section{Items Endorsed More Often by Men}

Animals should be used in all phases of biomedical research even when a solution or cure may seem very remote. $(M$ difference $=$ $.71, p=.004, r=.363)$

The use of animals in research is essential to improving human health and life quality. (M difference $=.70, p=.005, r=.349)$

New surgical procedures and experimental drugs should be tested on animals before they are used on people. $(M$ difference $=.55$, $p=.037, r=.259)$

Because many important questions cannot be answered by doing experiments on people, we are left with no alternative but to use animals in research. ( $M$ difference $=.52, p=.046, r=.248$ )

Boards that review requests for the use of animals in research are an effective safeguard against mistreatment of research animals. ( $M$ difference $=.353, p=.13, r=.184$ )

Curiosity about animal behavior or animal biology is ample justification for using animals in research. $(M$ difference $=.29, p=.249$, $r=.142)$

Most important biomedical breakthroughs are a consequence of using animals in research. $(M$ difference $=.23, p=.257, r=.14)$

Humans have a basic right to use animals in science, agriculture, and entertainment (zoo, circus animals, pets, etc.) as they see fit. ( $M$ difference $=.22, p=.362, r=.113$ )

\section{Items With No Disagreement Between Men and Women}

\section{Sample disagreed}

Only anti-intellectuals or otherwise questionable individuals would want to stop the use of animals in research. $(M=2.13)$

The use of animals in research has little or no bearing on problems confronting people. $(M=2.51)$

I would risk my life or reputation, or break the law, to save a suffering animal. $(M=2.79)$

People who want to stop or limit the use of animals in research are a threat to the future of science and medicine. $(M=3.0)$

A lot of important research is being blocked because of excessively strict regulations governing the use of animals in research. $(M=3.5)$

Most laboratory animals are better housed, fed, cared for, and protected from pain and suffering than many humans. $(M=3.38)$

Sample agreed

When determining the value of using animals in research, all of the past breakthroughs in science and medicine as well as all future benefits must be considered. $(M=4.7)$

If an important medical or scientific objective can only be met by using research animals, there is a moral obligation to conduct the research. $(M=4.5)$

Animals have a basic right to be free from suffering inflicted on them in research. $(M=4.3)$

Animals held in city pounds or animal shelters should be used in biomedical research if they are to be euthanized by the pounds or shelters. $(M=4.15)$

Sample was neutral

There are plenty of viable alternatives to the use of animals in research. $(M=3.5)$

Note. In parentheses, for each item that discriminated between the genders are (a) Mean differences between genders on the item ( $M$ difference); (b) p-values obtained from t-tests of differences between genders; and (c) the correlation between the item and the variable "gender," or function loadings. These items were rank ordered by the magnitude of their discriminant function loadings. For items that did not discriminate, only the overall $M$ for the sample appears in parentheses.

\footnotetext{
${ }^{a}$ Items are ordered by rank according to the degree of disagreement.
} 
Items that did not discriminate between genders. Twelve items did not discriminate between genders. The items that both men and women disagreed with seemed to validate this sample's self-reported moderate position on the use of animals in research. For instance, in general the sample believed that animal research in biomedical and psychological settings is relevant to the resolution of at least some problems humans face. Further, the sample did not express the desire to actively interfere with people involved in animal research, e.g., by breaking the law, or risking their reputation by publicly protesting animal research. Participants agreed that regulations governing animal use were important and were not detrimental to the progress of research. Findings also suggested that participants believed that the discussion of issues regarding the use of animals in research is important and should remain open.

Items that were agreed with by both men and women indicated that the majority of the sample thought that animals have a basic right to be free of the pain and suffering that can be inflicted on them in research. Despite this expressed belief that animals have a "basic right" to be free from research involving pain and suffering, participants favored animal research, believed there is a moral obligation to conduct research requiring the use of animals, and thought that pound animals should be used in biomedical research rather than being just euthanized.

Participants responded neutrally to one item: "There are plenty of viable alternatives to the use of animals in research" $(M=3.5)$. This neutral position may have been related to the finding that 35 students, or $25 \%$ of the sample, stated during the conduct of the study or while being debriefed that they did not know how to answer the question because they did not know if there were alternatives. This question seemed to be interpreted by the participants as more of a factual than an attitudinal question, and results suggested that the sample may have had little factual knowledge about the quality and availability of alternatives to animal use.

Overall, analysis of item contents appeared to reflect the belief held by both men and women in this sample that animal research is important to the solution of some problems, and that animal protectionists and regulations governing animal use do not excessively limit animal research. Men and women seemed to agree that if animals are to be killed anyway, using them in animal research is justified. Participants also agreed that animals have an intrinsic right to be free from suffering inflicted on them in painful or dangerous research.

\section{DISCUSSION}

In sum, women college students in this sample seemed to be more willing than men to make personal sacrifices to protect animal lives, were more likely than men to question biomedical research with animals on scientific grounds, reacted more emotionally and empathetically to the suffering of animals, and were generally more concerned about the plight of research animals. Women also saw a need for more restrictions on animal research. Overall, male participants had a stronger belief in the benefits of using research animals, and possibly this led them to feel less uncomfortable than women with using animals in research that may not result in an immediate or assured solution to biomedical or behavioral problems. Similarly, men's stronger belief in the benefits of biomedical research may have contributed to their disagreement with items suggesting that biomedical research is often invalid or unnecessary. Men seemed to be more convinced of future benefits, and more willing to sacrifice animals to achieve these benefits.

Jasper and Nelkin (1992) have attempted to explain gender differences such as these by suggesting that they are due to some extent to the persistence of traditional gender expectations. In this scenario, women are expected to be sensitive, compassionate, and gentle rather than aggressive. Based on her research on moral development, Gilligan (1982) suggested that there are at least two modes of moral judgment- 
one based on concern for rights and justice and one based on care and responsiveness to others. Gilligan suggested that the moral orientations of justice and care are found in both men and women, but a rights orientation is more common in men, whereas a caring perspective is more common in women.

According to Gilligan's (1982) view, impartiality, objectivity, and the distancing of the self from others so that fairness can be achieved form the basis of the justice perspective. Because everyone is assumed to be equal in regard to rights, basic needs, and duties, objective rules about what is just are considered applicable across situations. Rational principles, rather than emotions, are thought to appropriately govern moral behavior. In contrast, the care perspective assumes that moral problems are often interpersonal, situation-specific problems, which can be best resolved by understanding the feelings, relationships, and perspectives of the individuals involved. Love, sympathy, and empathetically responding to the needs of others are also thought to underlie ethical behavior. Thus, as opposed to deductions based on principles, the care perspective focuses more on individual needs and emotions in resolving ethical problems.

Despite some criticisms of Gilligan's research (see Kerber, Greeno, Maccoby, Luria, Stack, \& Gilligan, 1986), the notion of an ethical voice of care remains influential. For instance, Beauchamp and Childress (1994) suggested that the ethics of care has made an important contribution to current ethical theories generally, and particularly to biomedical ethics, by introducing the role of emotions:

Ethical theory since the late eighteenth century has exhibited a cognitivist proclivity; that is, it has regarded theory and moral judgment as the affairs of reason, rather than of emotion or passion ... The ethics of care corrects this cognitivist bias by giving the emotions a moral role. Having a certain emotional attitude and expressing the appropriate emotion in acting are morally relevant factors, just as having the appropriate motive for an action is morally relevant. The person who acts from rule-governed obligations without appropriately aligned feelings such as worry when a friend suffers seems to have a moral deficiency. In addition to expressing their feelings in their responses, agents also need to attend to the feelings of persons toward whom they act in moral relationships. Insight into the needs of others and considerate alertness to their circumstances often come from the emotions more than reason. In the history of human experimentation, for example, those who first recognized that some participants of research were being brutalized, subjected to misery, or placed at unjustifiable risk were persons who were able to feel compassion, disgust, and outrage through insight into the situation of these research participants. They exhibited emotional discernment of and sensitivity to the feelings of subjects, where others lacked comparable responses. (pp. 89-90)

Some of the findings of this study do seem to suggest that men and women differ in their ethical orientations toward animal research. For instance, the women cared more about individual research animals at a personal level as evidenced in their strong agreement with "It hurts me to see an animal in pain or psychological distress" and "I am very concerned about pain and suffering in animals." Similarly, women were more likely to express willingness to make personal sacrifices such as giving up meat and medical benefits in an effort to save animal lives.

Conversely, men seemed to agree with items reflecting an objective ethical orientation of justice. For example, men were much more likely to agree with the items "Animals should be used in all phases of biomedical research even when a solution or cure may seem very remote," and "Since many important questions cannot be answered by doing experiments on people, we are left with no alternative but to use animals in research." These items may indicate that the men based their moral decisions on the 
distancing of the self from research animals; application of objective moral principles, such as the principle that human life is more valuable than animal life; and the belief that benefit to human life outweighs concern for animal life.

Previous findings of gender differences in attitudes toward animal research have also been explained in terms of Gilligan's theory of moral development. Specifically, Kellert and Berry (1987) found differences in the knowledge, attitudes, and behaviors of men and women toward animals and suggested that "female moral emphasis on caring for intimates, nonaggressiveness, and compassion is consistent with our findings that women tend to assert strong emotional attachments to individual domestic animals" (p. 369).

In addition to possible differences in moral orientation, the findings of this study suggested that women were more likely than men to question the scientific merit of animal research. Given that women were more likely to see animal research in biomedical settings as repetitive, unnecessary, and invalid, it is not surprising that they tended to see review boards as ineffective and wanted to reduce the numbers of animals used in research. The findings of this study regarding women's greater skepticism about animal research are consistent with those of Galvin and Herzog ( 1992) who found that women, as compared to men, judged experiments on animals as more unethical and less morally justified, found precautions for research animals' welfare as insufficient, and were more likely to be emotionally upset by experimental procedures on animals because they found them to be cruel and inhumane.

Results of analyses of cross-cultural, religious, and political affiliation differences indicated that other factors, in addition to gender, may cultivate or be associated with a caring ethical orientation. Specifically, Native Americans, people of the Buddhist faith, and Democrats were more likely to endorse a pro-animal protection stance, in comparison to the other ethnic, political, and religious groups, as is indicated in their greater endorsement of items reflecting concern for research animals, opposition to animal research generally, personal discomfort about the use of animals in research, and favoring more restrictions on animal research. The sample sizes for the Native American and Buddhist groups were small and results should be taken tentatively and pursued in future studies. However, it is rare in social science research to get $100 \%$ endorsement of an item, which suggests that, though group differences on the scales were statistically nonsignificant, the pattern that emerged in analysis of individual items may warrant further investigation.

Findings of religious differences have been reported but have only compared the dominant religions in the United States, as opposed to Eastern religions. Similarly, political orientation has been well established as an important factor when investigating attitudes toward animal research (Driscoll, 1992). Specifically, Broida, Tingley, Kimball, and Miele (1993) found that provivisectionism was correlated with political conservatism, religious fundamentalism, and less empathy and concern for the welfare of animals. It would be interesting to compare the more traditional Western religions with those of the East in more detail and with a larger sample. It seems reasonable to suggest that the emphasis of many Eastern philosophies and religions on compassion and limiting the suffering of sentient beings contributes to differences in ethical orientation and attitudes toward animal research among people of these diverse backgrounds.

Finally, a brief note should be made on the characteristics of the measure used. Exploratory factor analysis suggested that the ARQ is multidimensional. Three moderately correlated factors emerged: the pro-research factor, the animal protection factor, and the extreme pro-research factor. The high reliabilities of the pro-research and animal protection factors were encouraging in terms of their usefulness for future investigations into the multifaceted nature of attitudes toward animal research. The extreme pro-research factor was an unexpected finding. The low reliability of this factor suggests that it 
may be worthwhile to expand the ARQ to include a more diverse range of attitudes toward animal research.

\section{REFERENCES}

Beauchamp, T. L., \& Childress, J. F. (1994). Principles of biomedical ethics (4th ed.). New York: Oxford University Press.

Broida, J., Tingley, L., Kimball, R., \& Miele, J. (1993). Personality differences between pro- and antivivisectionists. Society and Animals, 1(2), 129-143.

Driscoll, J. W. (1992). Attitudes toward animal use. Anthrozoos, 5(1), 32-39.

Gallup, G. G., \& Beckstead, J. W. (1988). Attitudes toward animal research. American Psychologist, 43(6), 474-476.

Galvin, S. L., \& Herzog, H. A. (1992). The ethical judgment of animal research. Ethics and Behavior, 2, 263-286.

Gilligan, C. (1982). In a different voice: Psychological theory and women's development. Cambridge, MA: Harvard University Press.

Herzog, H. A., Betchart, N. S., \& Pittman, R. B. (1991). Gender, sex role orientation, and attitudes toward animals. Anthrozoos, 4, 184-191.

Herzog, H. A., \& Galvin, S. (in press). Common sense and the mental lives of animals: An empirical approach. In R. Mitchell (Ed.), Anthropomorphism, anecdotes, and animals. Lincoln: University of Nebraska Press.

Jasper, J. M., \& Nellcin, D. (1992). The animal rights crusade: The growth of a moral protest. New York: The Free Press.

Kellett, S. R., \& Berry, J. K. (1987). Attitudes, knowledge, and behaviors toward wildlife as affected by gender. Wildlife Society Bulletin, 15,363-371.

Kerber, L. K., Greeno, C. G., Maccoby, E. E., Luria, Z., Stack, C. B., \& Gilligan, C. (1986). On in a different voice: An interdisciplinary forum. Signs: Journal of Women in Culture and Society, 1 /(2), 304-333.

Pifer, L., Shimizu, K., \& Pifer, R. (1994). Public attitudes toward animal research: Some international comparisons. Society and Animals, 2, 95-114.

Pious, S. (1991). An attitude survey of animal rights activists. Psychological Science, 2(3), 194-196. 


\section{APPENDIX 1: THE ANIMAL RESEARCH QUESTIONNAIRE}

\section{Animal Protection scale}

1. The use of animals in research has little or no influence on problems confronting people.

2. I am very concerned about pain and suffering in animals.

3. I have seriously considered becoming a vegetarian in an effort to save animal lives.

4. There are plenty of viable alternatives to the use of animals in research.

5. Most psychological research done on animals is invalid and unnecessary.

6. We need more regulations governing the use of animals in research.

7. The use of animals in biomedical research cannot be justified and should be stopped.

8. Most biomedical research done on animals is repetitive, unnecessary, and invalid.

9. Animals have a basic right to be free from suffering inflicted on them in research.

10. Alternatives to using animals in research should be employed even if they are less effective than animal models.

11. I would risk my life or reputation, or break the law to save a suffering animal.

12. We should reduce the number of animals used in research, make our techniques less painful and dangerous, or use alternatives to research animals whenever possible.

13. There are no moral grounds to justify inflicting harm on animals in an attempt to benefit human beings.

14. It hurts me to see an animal in pain or psychological distress.

15. Human and animal life are equally valuable.

16. If it were up to me, all use of animals in painful or dangerous research would be stopped today.

\section{Research scale}

1. Because many important questions cannot be answered by doing experiments on people, we are left with no alternative but to use animals in research.

2. New surgical procedures and experimental drugs should be tested on animals before they are used on people.

3. Most important biomedical breakthroughs are a consequence of using animals in research.

4. Most laboratory animals are better housed, fed, cared for, and protected from pain and suffering than many humans.

5. Curiosity about animal behavior or animal biology is ample justification for using animals in research.

6. If an important medical or scientific objective can only be met by using research animals, there is a moral obligation to conduct the research.

7. The use of animals in research is essential to improving human health and life quality.

8. Boards that review requests for the use of animals in research are an effective safeguard against the mistreatment of research animals.

9. Animals should be used in all phases of biomedical research even when a solution or cure may seem very remote.

10. Animals held in city pounds or animal shelters should be used in biomedical research if they are to be euthanized by the pounds or shelters.

11. When determining the value of using animals in research, all of the past breakthroughs in science and medicine as well as all future benefits must be considered.

12. Animals used in biomedical research do not feel as much pain as would humans used in the same research.

13. Humans have a basic right to use animals in science, agriculture, and entertainment as they see fit.

14. Only anti-intellectuals or otherwise questionable individuals would want to stop or limit the use of animals in research.

15. Much important research is being blocked because of excessively strict regulations governing the use of animals in research.

16. People who want to stop or limit the use of animals in research are a threat to the future of science and medicine. 


\section{APPENDIX 2: FACTORS AND ITEM LOADINGS}

\section{Pro-Research}

76. Because many important questions cannot be answered by doing experiments on people, we are left with no alternative but to use animals in research.

75. The use of research animals is essential to improving human health and life quality.

-73. The use of animals in biomedical research cannot be justified and should be stopped.

71. If an important medical or scientific objective can only be met by using animals in research, there is a moral obligation to conduct the research.

70. Most important biomedical breakthroughs are a consequence of using animals in research.

-66. Most biomedical research done on animals is repetitive, unnecessary, and invalid.

64. When determining the value of using animals in research, all of the past breakthroughs in science and medicine as well as all future benefits must be considered.

-64. If it were up to me, all use of animals in dangerous or painful research would be stopped today.

-62. The use of animals in research has little or no bearing on problems confronting people.

60. New surgical procedures and experimental drugs should be tested on animals before they are used on people.

58. People who want to stop or limit the use of animals in research are a threat to the future of science and medicine.

39. Animals held in city pounds or animal shelters should be used in biomedical research if they are to be euthanized by the pounds or shelters.

\section{Protection}

76. We should reduce the number of animals used in research, make our techniques less painful and dangerous, or use alternatives to research animals whenever possible.

75. I am very concerned about pain and suffering in animals.

72. Animals have a basic right to be free of suffering inflicted on them in research.

70. We need more regulations governing the use of animals in research.

70. It hurts me to see an animal in pain or psychological distress.

50. Alternatives to using animals in research should be employed even if they are less effective than animal models.

32. I have seriously considered becoming a vegetarian in an effort to save animal lives.

\section{Extreme}

76. Animals used in biomedical research do not feel as much pain as would humans used in the same research.

52. A lot of important research is being blocked because of excessively strict regulations governing the use of animals in research.

51. Most laboratory animals are better housed, fed, cared for, and protected from pain and suffering than many humans. 